\title{
SHORT-WAVE DIATHERMY IN PATIENTS WITH CHRONIC LOW BACK PAIN: A SYSTEMATIC REVIEW
}

\author{
DIATERMIA POR ONDAS CURTAS EM PACIENTES COM DOR LOMBAR CRÔNICA: \\ REVISÃO SISTEMÁTICA
}

\section{DIATERMIA POR ONDAS CORTAS EN PACIENTES CON DOLOR LUMBAR CRÓNICO: REVISIÓN SISTEMÁTICA}

\author{
Luis Henrique Paladini, ${ }^{1}$ Nicole Almeida, ${ }^{10}$ Raciele Ivandra Guarda Korelo, ${ }^{1}$ Rafael Michel de Macedo, ${ }^{2}$ Luiz Cesar Guarita-Souza, ${ }^{3}$ \\ talta Gianello Gnoato Zotz, ${ }^{1}$ Ana Carolina Brandt de Macedo ${ }^{1}$ \\ 1. Universidade Federal do Paraná, Department of Prevention and Rehabilitation in Physiotherapy, Curitiba, PR, Brazil. \\ 2. Hospital Cardiológico Costantini, Curitiba, Paraná, Brazil. \\ 3. Pontifícia Universidade Católica do Paraná, Curitiba, PR, Brazil.
}

\begin{abstract}
The aim of this study was to evaluate the evidence of application of short-wave diathermy (SWD) in individuals with chronic low back pain (CLBP) and its prescription parameters. The data sources (MEDLINE, PubMed, LILACS, DARE, PsycINFO, AusportMed, SciELO, PEDro and the Cochrane Central Register of Controlled Trials) were systematically searched for articles published up to December 2017. Randomized and non-randomized clinical trial studies that investigated the effect of the application of SWD on CLBP were selected. Two independent reviewers assessed the risk of bias in studies using the Jadad and the Downs \& Black scales. Five studies (731 patients) were included, all of whom presented improvements in CLBP. The majority used continuous mode SWD, with only one using pulsed mode (82 and $200 \mathrm{~Hz}$ ). SWD produced improvements in CLBP, but there is limited evidence for its application, and a lack of standardization of the parameters used. Furthermore, the results that address this topic should be interpreted with caution due to their low methodological quality and limited number. Level of evidence II; Systematic review.
\end{abstract}

Keywords: Low Back Pain; Diathermy; Systematic review.

\section{RESUMO}

O objetivo do presente estudo foi avaliar a evidência de aplicação da diatermia por ondas curtas (DOC) em indivíduos com dor lombar crônica (DLC) e seus parâmetros de prescrição. As fontes de dados (MEDLINE, PubMed, LILACS, DARE, Psyc/NFO, AusportMed, SciELO, PEDro e Cochrane Central Register of Controlled Trials) foram pesquisadas sistematicamente quanto aos artigos publicados até dezembro de 2017. Estudos de ensaios clínicos randomizados e não randomizados que investigaram o efeito da aplicação da DOC na DLC foram selecionados. Dois revisores independentes avaliaram o risco de viés em estudos usando as escalas Jadad e Downs \& Black. Cinco estudos (731 pacientes) foram incluídos e todos apresentaram melhora na DLC. A maioria usou a DOC de modo contínuo, com apenas um utilizando o modo pulsado (82 e $200 \mathrm{~Hz}$ ). A DOC apresentou melhora na DLC, no entanto, há evidências limitadas para sua aplicação e ausência de padronização dos parâmetros utilizados. Além disso, os resultados que se referem a esse tópico devem ser interpretados com cautela devido à baixa qualidade metodológica e ao número limitado de estudos. Nível de evidência II; Revisão sistemática.

Descritores: Dor lombar; Diatermia; Revisão sistemática.

\section{RESUMEN}

El objetivo del presente estudio fue evaluar la evidencia de la diatermia por ondas cortas (DOC) en individuos con dolor lumbar crónico (DLC) y sus parámetros de prescripción. Las fuentes de datos (MEDLINE, PubMed, LILACS, DARE, PsycINFO, AusportMed, SCiELO, PEDro y Cochrane Central Register of Controlled Trials) fueron utilizadas para búsquedas sistemáticas de artículos publicados hasta diciembre de 2017. Fueron seleccionados los estudios de ensayos clínicos aleatorizados y no aleatorizados que investigaron el efecto de la aplicación de DOC en DLC. Dos revisores independientes evaluaron el riesgo de sesgo en estudios usando las escalas Jadad y Downs \& Black. Fueron incluidos cinco estudios (731 pacientes) y todos presentaron mejora en DLC. La mayoría usó la DOC de modo continuo, con sólo uno usando el modo pulsado (82 y $200 \mathrm{~Hz}$ ). La DOC produjo mejoras en DLC, sin embargo, hay evidencias limitadas para su aplicación y ausencia de estandarización de los parámetros utilizados. Además, los resultados que se refieren a ese tópico deben interpretarse con cautela debido a la baja calidad metodológica y al número limitado de estudios. Nivel de evidencia II; Revisión sistemática.

Descriptores: Dolor de la región lumbar; Diatermia; Revisión sistemática. 


\section{INTRODUCTION}

Chronic low back pain (CLBP) affects about $85 \%$ of the world's population at some point in their lives and is responsible for generating work losses and high public health expenditures, as well as negatively influencing people's mental health and quality of life..$^{1,2}$

The guidelines ${ }^{3-6}$ on non-pharmacological treatment of low back pain recommend different physical therapies that can be used as part of a physical therapy program. Some examples are: physical exercise, posture training, spinal manipulation, acupuncture, massage therapy, and the application of physical agents such as short-wave diathermy (SWD). SWD is one of the oldest electrothermotherapeutic modalities. However, studies on the topic present low methodological quality. Chou and Huffman ${ }^{7}$ found only two studies related to the application of SWD in subjects with low back pain, with low levels of evidence and without adequate descriptions of the parameters used. Therefore, this study aimed to perform a systematic review of the scientific evidence for the application of SWD in individuals with chronic low back pain, and its prescription parameters.

\section{METHODS}

\section{Eligibility criteria}

Randomized and non-randomized clinical trials comparing continuous and/or pulsed application of short waves to other interventional methods, such as exercise, osteopathy and traction, or to a placebo group, were included. The target population was individuals with chronic low back pain. The following outcomes were evaluated: pain visual analogue scale (VAS), Lattinen's score, ${ }^{8}$ Tenderness score, ${ }^{9}$ pain characteristics, straight leg raise, lumbar flexion and subjective effect of the treatment.

The exclusion criteria were: (1) retrospective studies, (2) literature reviews, (3) not finding the full article and (4) studies in a language other than Portuguese, Spanish or English.

\section{Search and selection strategy}

The search was performed independently and in duplicate, using the electronic databases of MEDLINE, PubMed, LILACS, DARE, PsycINFO, AusportMed, SciELO, PEDro and the Cochrane Central Register of Controlled Trials (Cochrane CENTRAL). Articles published from 1985 to October 2016 were included, and studies in Portuguese, Spanish and English were considered

The following keywords were used: low back pain, short wave diathermy, short wave therapy, short wave therapies, deep heat, lumbar pain, chronic lumbar pain, chronic low back pain, pulsed short wave diathermy and nonthermal short wave therapy. The search terms were grouped with a high sensitivity combination of words used in the search for clinical trials. The complete search strategy used for the MEDLINE database followed the recommendations of Moher et al. ${ }^{10}$ Details of the other search strategies used are available upon request.

All titles and abstracts were selected in duplicate by two independent researchers (NA and LHP). The systematic review was performed in phases. Initially, all the publications available in the databases selected according to each descriptor were searched. In the second phase, a more rigorous analysis was conducted in which only the titles were selected. After excluding all the articles that did not fit the study criteria, a new search was performed based on the abstracts of the selected articles. All abstracts that did not provide sufficient information to ascertain whether they met the inclusion and exclusion criteria were selected for evaluation of the full text. Both researchers compared the identified articles and by consensus, defined which ones would be retrieved for reading of the full text. When a consensus was not reached, a third researcher (ACBM) was consulted.

\section{Data Extraction}

Using standardized forms, the same two reviewers independently conducted the data extraction, considering the methodological characteristics of the studies, the interventions and the outcomes; differences were also resolved by consensus. The results of interest were the pain visual analogue scale (VAS) scores, tender points, Lattinen's score, straight leg raising, lumbar flexion, pain severity, and subjective effect of the treatment.

\section{QUALITY ANALYSIS}

\section{Evaluation of the risk of bias}

Two researchers (NA and LHP) independently assessed the quality of the studies using the Jadad Scale $\mathrm{e}^{11,12}$ and the Downs \& Black Scale. ${ }^{13}$ When there was no consensus, a third researcher (ACBM) was consulted.

The Jadad Scale ${ }^{11,12}$ is a validated scale initially created for studies related to "pain", which investigates whether the study was properly described and considered appropriate. It scores the quality of a study on a five-point scale: (1) description of the randomization; (2) description of the double blinding; (3) description of losses; (4) appropriate randomization and (5) appropriate blinding. Studies that have a score of 0 to 2 are classified as having low quality, while those with scores between 3 and 5 are characterized as having high quality.

The Downs \& Black ${ }^{13}$ scale is considered a methodologically strong scale, as it is more flexible than the other scales and has the advantage that it evaluates the strengths and weaknesses of the study. Five sub-scales are evaluated, related to reporting, external validation, biases, confounding factors and power of the study. For each "yes" answer in the scale, a point is added, with a possible total of 28 points. Scores of 26-28 are considered "Excellent", 20-25 "Good," 15-19 "Medium" and below 14 points, "Poor".

\section{RESULTS}

\section{Description of the studies}

The literature search identified a total of 9961 articles in the selected databases. After screening for titles, 9948 articles were excluded, leaving only 13 for reading of the abstracts; of these, a further eight were excluded (seven due to duplication and one because it was a systematic review), leaving five articles to be read in full. (Figure 1) Table 1 presents the characteristics of the studies evaluated. These included 731 patients who had suffered from low back pain for more than 3 months, of whom 254 (35\%) had received SWD, 293 (40\%) had undergone other treatments, and 184 (25\%) had been allocated to the SWD placebo group.

\section{Bias' risk}

The studies were classified using two different scales: the Jadad scale and the Downs \& Black scale. All the studies presented low bias scores. Through the Jadad scale, three articles were classified with a score of $0,9,14,15$ one study with a score of $1^{16}$ and one study with a score of $2 .^{8}$ The main weakness detected through the Jadad scale was the lack of description regarding the double-blind character and description of the randomization method. (Table 2) Through the Downs \& Black scale, two studies were classified with medium bias $^{15,16}$ and the other three studies with poor bias. ${ }^{8,9,14}$ (Table 3)

Of the articles included $(n=5)$, all presented randomization; however, only three studies ${ }^{9,14,15}$ described the form of randomization, one presented the description of the blinding, and three $8,14,16$ showed the losses and exclusions.

\section{Pain evaluation}

Of the five articles analyzed, four used the VAS as the pain evaluation instrument. However, each study used a different type of scale and different methods of analysis. Only one article ${ }^{16}$ performed an analysis of the pain intensity and a subjective analysis of the treatment, without using the VAS.

Gibson et al. ${ }^{14}$ used the millimetric VAS $(0-100 \mathrm{~mm})$ and found that the SWD group had significant improvement in pain after 4 weeks but did not compare this with the osteopathy group, which also showed a significant improvement. 
Wagstaff et al..$^{15}$ applied a 0-15 cm VAS, finding significant results between moments before and after treatment (after 3 weeks). Participants in the continuous SWD group presented an improvement in pain of $31.56 \%$, those in the pulsed $82 \mathrm{~Hz} / 700 \mathrm{~W}$ SWD group presented a reduction in pain of $47.05 \%$ and the other pulsed $200 \mathrm{~Hz} / 300 \mathrm{~W}$ SWD group presented a reduction of $68.31 \%$. There was a significant difference between the continuous and pulsed mode. However, there was no difference between the two types of pulsed SWD.

Ahmed et al. ${ }^{9}$ and Shakoor et al..$^{8}$ used the VAS. However, the

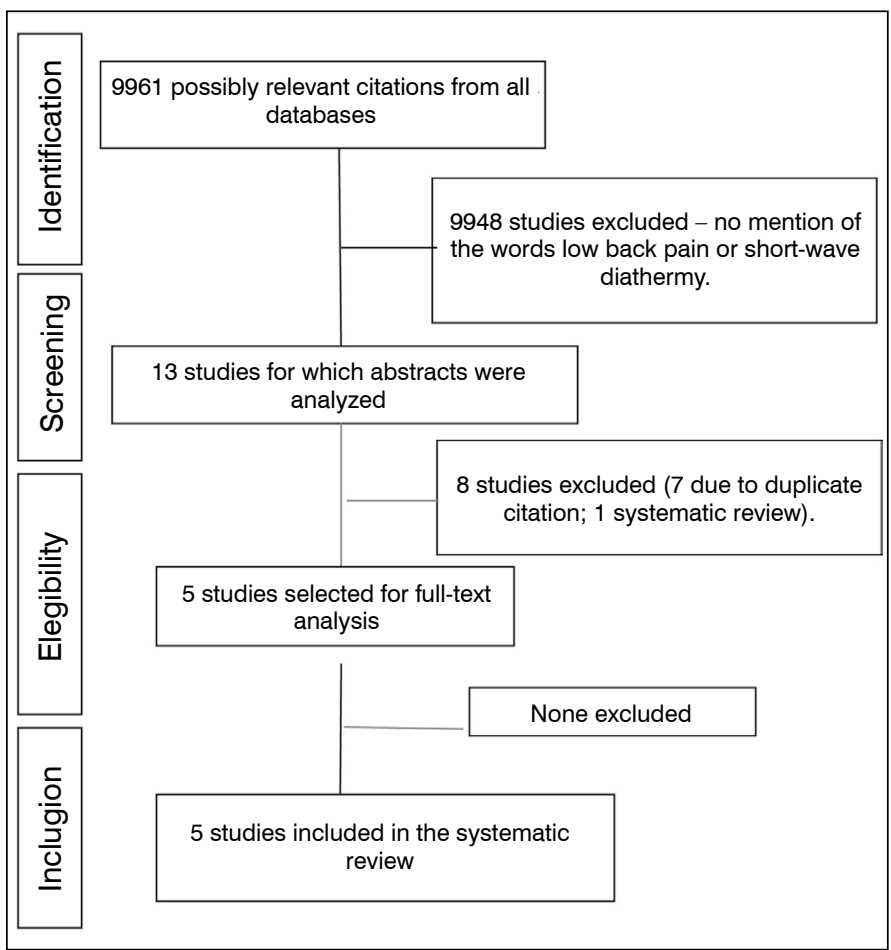

Figure 1. Steps performed in the selection process and reasons for exclusion. analysis of pain outcome was performed together with other outcomes, and so it was not possible to verify the individual improvement in this symptom. In all the studies, the participants presented improvements in pain, independently of the group to which each one belonged (100\%), ${ }^{8,9,14-16}$

\section{Lattinen's Test Score}

Ahmed et al. ${ }^{9}$ and Shakoor et al. ${ }^{8}$ used the Lattinen's test score as their outcome. However, the analysis was not performed in isolation. Ahmed et al. ${ }^{9}$ performed the analysis together with the VAS and the tenderness score, and observed significant improvements in the treatment group compared to the placebo group from the $2^{\text {nd }}$ to the $6^{\text {th }}$ weeks. The treatment group presented a reduction of $68.5 \%$, when comparing the pre-treatment evaluation score and that of the final week of short-wave application. The authors did not describe the mode of use of the SWD, only indicating the time (15 min), number of times weekly ( 3 times) and total length of treatment ( 6 weeks). Shakoor et al. ${ }^{8}$ analyzed the Lattinen's test score together with the VAS and found significant difference in both groups (placebo and treatment) in the intragroup analysis, with significant improvement in the treatment group compared to the placebo group after the $3^{\text {rd }}$ to the $6^{\text {th }}$ weeks of intervention. The SWD protocol $(27.33 \mathrm{MHz})$ consisted of the continuous, capacitive method for 15 min, 3 times a week, for 6 weeks.

\section{Tenderness Score}

As previously described, Ahmed et al. ${ }^{9}$ used the tenderness score. However, it was not possible to analyze this outcome in isolation because it was evaluated with other variables.

\section{Other outcomes}

The outcomes assessed, such as the lumbar flexion ${ }^{14}$ and the straight leg raise, ${ }^{8}$ were not included in the analysis of the results of the articles and it was not possible to verify the influence of the SWD on these parameters. In the study by Sweetman et al. ${ }^{16}$ which evaluated the subjective effect of the treatment, there were improvements in all treatment groups (control, SWD, traction and exercise); however, there was no significant difference between them.

Table 1. Study characteristics.

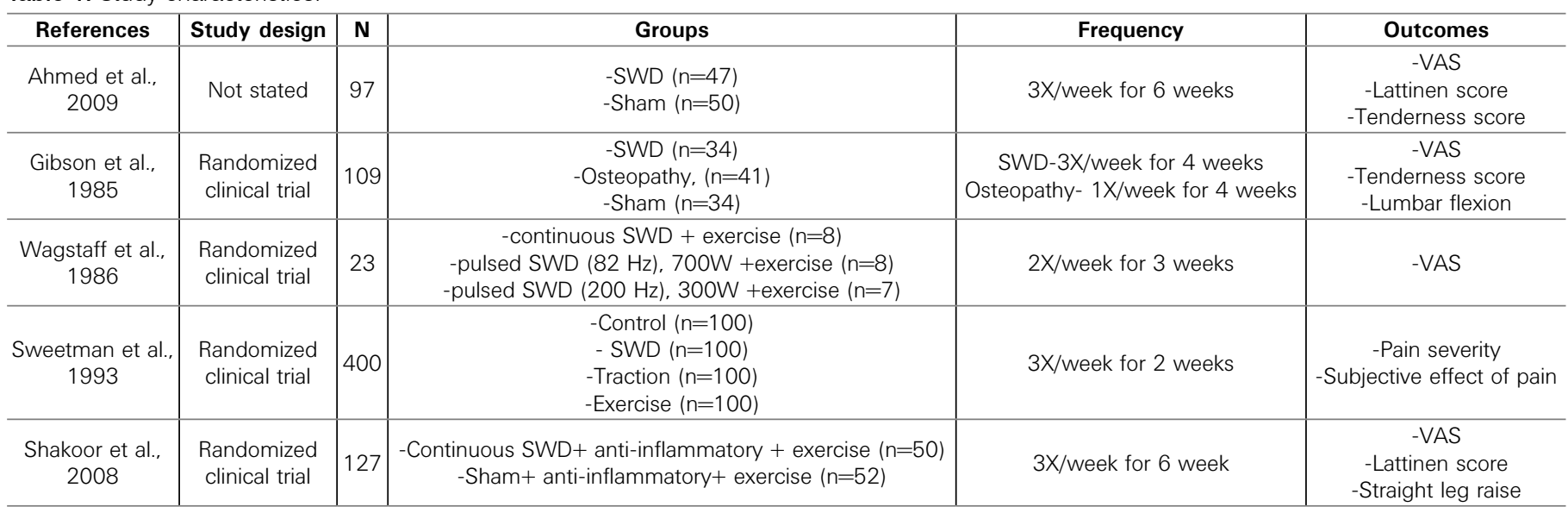

$\mathrm{N}$ - number of patients; SWD- short wave diathermy; VAS- pain visual analogue scale

Table 2. Bias' Risk for the included studies and JADAD classification.

\begin{tabular}{c|c|c|c|c|c|c}
\hline References & Randomization & $\begin{array}{c}\text { Description of } \\
\text { Randomization } \\
\text { Method }\end{array}$ & Blinding & $\begin{array}{c}\text { Description } \\
\text { of Blinding } \\
\text { Method }\end{array}$ & $\begin{array}{c}\text { Description } \\
\text { of Losses }\end{array}$ & $\begin{array}{c}\text { JADAD } \\
\text { Classification }\end{array}$ \\
\hline Ahmed et al., $\mathbf{2 0 0 9}$ & Yes & No & No & No & No & Poor quality \\
\hline Gibson et al., $\mathbf{1 9 8 5}$ & Yes & Yes & No & No & Yes & Poor quality \\
\hline Wagstaff et al., $\mathbf{1 9 8 6}$ & Yes & No & No & No & No & Poor quality \\
\hline Sweetman et al., $\mathbf{1 9 9 3}$ & Yes & Yes & No & No & Yes & Poor quality \\
\hline Shakoor et al., $\mathbf{2 0 0 8}$ & Yes & Yes & No & No & Yes & Poor quality \\
\hline
\end{tabular}


Table 3. Downs \& Black Classification.

\begin{tabular}{|c|c|c|c|c|c|}
\hline Question & \begin{tabular}{|c|} 
Ahmed \\
et al., 2009
\end{tabular} & $\begin{array}{c}\text { Gibson } \\
\text { et al., } 1985\end{array}$ & \begin{tabular}{|c|} 
Wagstaff \\
et al., 1986
\end{tabular} & $\begin{array}{l}\text { Sweetman } \\
\text { et al., } 1993\end{array}$ & $\begin{array}{c}\text { Shakoor } \\
\text { et al., } 2008\end{array}$ \\
\hline 1 & Yes & Yes & Yes & Yes & No \\
\hline 2 & No & No & Yes & Yes & No \\
\hline 3 & Yes & Yes & Yes & Yes & Yes \\
\hline 4 & No & Yes & Yes & Yes & No \\
\hline 5 & No & UD & UD & UD & UD \\
\hline 6 & Yes & UD & Yes & Yes & Yes \\
\hline 7 & Yes & Yes & Yes & Yes & Yes \\
\hline 8 & No & No & No & No & No \\
\hline 9 & No & Yes & No & No & Yes \\
\hline 10 & Yes & No & Yes & Yes & Yes \\
\hline 11 & UD & UD & No & UD & UD \\
\hline 12 & UD & UD & No & UD & UD \\
\hline 13 & UD & No & No & No & No \\
\hline 14 & Yes & UD & UD & No & No \\
\hline 15 & UD & UD & UD & No & No \\
\hline 16 & UD & UD & Yes & Yes & UD \\
\hline 17 & Yes & Yes & Yes & Yes & Yes \\
\hline 18 & No & Yes & Yes & Yes & Yes \\
\hline 19 & Yes & Yes & Yes & Yes & Yes \\
\hline 20 & Yes & UD & Yes & Yes & Yes \\
\hline 21 & UD & Yes & Yes & Yes & Yes \\
\hline 22 & UD & Yes & Yes & Yes & Yes \\
\hline 23 & Yes & Yes & Yes & Yes & Yes \\
\hline 24 & No & No & UD & UD & No \\
\hline 25 & Yes & UD & UD & UD & UD \\
\hline 26 & UD & Yes & Yes & Yes & No \\
\hline 27 & No & No & No & No & No \\
\hline
\end{tabular}

UD- unable to determine.

\section{DISCUSSION}

This systematic review has shown that there is limited evidence regarding the effects of SWD on chronic low back pain, with few articles related to this symptomatology, and those that do exist having low methodological quality. This is in line with the findings of Shields et al., ${ }^{17}$ who reviewed clinical trials and concluded that the studies on this resource presented mixed quality and were published a long time ago, with few studies being published in the last fifteen years. In addition, the author claims that due to the lack of studies on SWD, and because it is not as affordable and economical as other equipment, it is often replaced by Low-Level Laser Therapy (LLLT) or by Interferential Current Therapy.

In order to evidence the effects produced by the SWD application, all parameters must be correctly described, including: power, pulse frequency, emission mode and duration of application. ${ }^{16}$ Of the protocols presented in the studies included in this systematic review, the majority $(60 \%, n=3)^{8,9,14}$ used 15 minute applications and 3 applications per week $(80 \%, n=4))^{8,9,14,16}$ Regarding the frequency of the equipment, only $40 \%(n=2)$ of the studies ${ }^{8,16}$ described this aspect. Shakoor et al. ${ }^{8}$ used the capacitive mode, with capacitor pads, at a frequency of $27.33 \mathrm{MHz}$. Wagstaff et al. ${ }^{15}$ used a frequency of $27.12 \mathrm{MHz}$ for the three participating groups, altering only the pulsed or continuous mode. Regarding the duration of the protocol, two studies ${ }^{8,9}$ applied it for 6 weeks, one study ${ }^{14}$ for 4 weeks, another ${ }^{15}$ for 3 weeks and the fifth, ${ }^{16}$ for 2 weeks. The total number of sessions presented wide variation, with $6,{ }^{15,16} 12^{14}$ and $18^{8,9}$ sessions. Regardless of the number of sessions or length of treatment, improvement in lumbar pain was found.

Short wave diathermy can be applied in continuous or pulsed mode. ${ }^{18,19}$ Continuous SWD promotes analgesia through deep heating, increasing the elasticity of the connective tissue, causing dilation of the arterioles and capillaries and consequently increasing blood flow in the pain area ${ }^{18,20}$ Pulsed SWD promotes increased blood flow, decreases joint pain and stiffness, reduces inflammation, accelerates the healing process, improves tissue repair and accelerates the resolution of edema. ${ }^{21} \mathrm{Al}$ Mandeel and Watson ${ }^{22}$ examined the effects of high and low power (24W and 3W respectively) and demonstrated significant physiological effects of increased blood volume and skin temperature, primarily through the high-power treatment.

Regarding the mode of emission, all the authors ${ }^{8,9,14-16}$ used continuous SWD $(n=5)$. However, one author ${ }^{15}$ also used pulsed SWD. Although there is no standard therapy for the treatment of CLBP, there is evidence that SWD applied in continuous mode results in greater responses in chronic clinical conditions, while in pulsed mode, it has better results in acute wounds. ${ }^{17}$ This conflicts with the findings of Wagstaff et al., ${ }^{15}$ whose results of a decrease in CLBP were better with the application of the pulsed mode (82 and $200 \mathrm{~Hz}$ ), regardless of frequency. However, the lack of placebo group, and the small number of participants $(n=23)$, limit the evidence found in that study. Kerem and Yigiter ${ }^{23}$ also compared three modes of operation (continuous, pulsed at $200 \mathrm{~Hz}$ and pulsed at $46 \mathrm{~Hz}$ ) and found significant improvements in the groups treated with the pulsed mode, with no difference between them. Although this study used a larger sample of patients $(n=60)$, there was no placebo group. Therefore, there is still no evidence regarding the best mode of emission. Durmus et al. ${ }^{24}$ used continuous microwave diathermy in patients with low back pain and did not find any significant difference in relation to the group that only performed exercise.

Of the five articles analyzed, four $r^{8,9,14,16}$ compared the shortwave to the placebo group, and two ${ }^{8,9}$ indicated improvements in the continuous SWD group. One article ${ }^{14}$ found no difference between the groups and one, ${ }^{16}$ despite including a placebo group, did not perform a comparative analysis. Gibson et al. ${ }^{14}$ related the positive results in the placebo group to the conviction about the treatment. Another justification used in the literature for cases in which there is improvement in the placebo group is the expectation of a reduction in the pain, stimulating the production of endorphins, which act in the same morphine analgesic receptor sites in the cerebral regions. This improvement may also be related to stimulation of dopaminergic circuits and inhibition of prostaglandin-dependent and cholecystokinase-dependent circuits. ${ }^{25}$

Evidence suggests ${ }^{1,2,6}$ that treatment for low back pain should not be carried out in isolation, but rather, in association with the use of electrothermophototerapeutic resources and exercise, as found in the studies by Wagstaff et al. ${ }^{15}$ and Shakoor et al. ${ }^{8}$ The latter also associated it with the use of anti-inflammatory agents. Wagstaff et al. ${ }^{15}$ associated SWD with pelvic anteroposterior and retroversion exercises, bridge, lumbar extension, prone hip extension, knee flexion, and isometric contraction of the abdomen. Shakoor et al. ${ }^{8}$ associated SWD with spinal extension and strengthening exercises. As there was no isolated comparison of the treatments, it was not possible to verify whether the association of the SWD with exercises provided greater efficacy of the treatment. Kerem and Yigiter ${ }^{23}$ also associated the application of continuous and pulsed SWD with exercise; however, they do not give details of the type of exercise, only reporting that stretching, strengthening and postural exercises were performed. In terms of results, the authors verified that pulsed SWD was more efficient for pain relief. In the study by Jayaram et al. ${ }^{26}$ SWD was used for 20-30 minutes for 8 weeks; in one group, the treatment was associated with abdominal strengthening exercises and in the other, with lumbar extension exercises. The authors concluded that SWD associated with abdominal exercises was more effective; however, the study was not randomized and there was no placebo group. The study of Khan et al. ${ }^{27}$ also compared the application of SWD associated with exercise (aerobic warm-up for 6 minutes, 15 stretches for the whole body and strengthening exercises for the back, abdomen and hip, 3 times a week, for 6 weeks) and found that the association of SWD was more efficient for symptom relief than exercise alone.

Corroborating the review by Shields et al., ${ }^{17}$ this systematic review found that there have been many studies on short-wave 
diathermy, but these do not present effective evaluation methods. When associated with the descriptor "low back pain", as in this review, the number of articles is greatly reduced.

Although the selected studies were published across a long time-interval, there were no advances in methodological quality. Shields et al. ${ }^{17}$ found that much evidence for short-wave diathermy can be found. However, the studies do not have effective evaluation methods, which contributes to the reduced use of this equipment by physiotherapists.

\section{CONCLUSION}

There is a lack of studies on the application of SWD for low back pain, and the existing literature presents poor methodological quality and early publication dates (1985-2009). Despite the technological advances in the equipment, there has been a decrease in the use of this resource. Thus, the present systematic review found that there is insufficient evidence to indicate the use of SWD for the treatment of chronic low back pain. The poor methodological quality of the articles suggests that new randomized clinical trials are needed on this subject, with a special focus on the prescription parameters for SWD. The studies should be planned with greater methodological rigor, include a larger number of patients, and present better details of the prescription parameters.

All authors declare no potential conflict of interest related to this article.

CONTRIBUTION OF THE AUTHORS: Each author made significant individual contributions to this manuscript. LHP: search for articles, introduction, methodology, discussion and conclusion. NA: search for articles, methodology, discussion and conclusion. TGZ: review of articles. RIGK: review of articles. RMM: review of articles. LCGS: review of articles. ACBM: search for articles, introduction, methodology, discussion and conclusion.

\section{REFERENCES}

1. Delitto A, George, SZ, Dillen LV, Whitman JM, Sowa G, Shekelle P, et al. Low Back Pain Clinical Practice Guidelines Linked to the International Classification of Functioning, Disability, and Health from the Orthopaedic Section of the American Physical Therapy Association. $J$ Orthop Sports Phys Ther. 2012;42(4):A1-57.

2. Chou R, Qaseem A, Snow V, Casey D, Cross JT, Shekelle P, et al. Diagnosis and Treatment of Low Back Pain: A Joint Clinical Practice Guideline from the American College of Physicians and the American Pain Society Diagnosis and Treatment of Low Back Pain. Ann Inter Med. 2007;147(7):478-91

3. Chou R, Loeser JD, Owens DK, Rosenquist RW, Atlas SJ, Baisden J, et al. Interventiona therapies, surgery, and interdisciplinary rehabilitation for low back pain: an evidence-based clinical practice guideline from the American Pain Society. Spine (Phila Pa 1976). 2009:34(10):1066-77

4. Arnau JM, Vallano A, Lopez A, Pellisé F, Delgado MJ, Prat N. A critical review of guidelines for low back pain treatment. Eur Spine J. 2006;15(5):543-53

5. Airaksinen O, Brox JI, Cedraschi C, Hildebrandt J, Klaber-Moffett J, Kovacs F, et al. Chapte 4 European guidelines for the management of chronic nonspecific low back pain. Eur Spine J. 2006;15 Suppl 2:S192-300.

6. Qaseem A, Wilt TJ, McLean RM, Forciea MA. Noninvasive Treatments for Acute, Subacute, and Chronic Low Back Pain: A Clinical Practice Guideline From the American College of Physicians Noninvasive Treatments for Acute, Subacute, and Chronic Low Back Pain. Ann Inter Med. 2017;166(7):514-30.

7. Chou R, Hufflman LH. Nonpharmacologic Therapies for Acute and Chronic Low Back Pain: A Review of the Evidence for an American Pain Society/American College of Physicians clinical practice guideline. An Int Med. 2007;147(7):492-504

8. Shakoor MA, Rahman MS, Moyeenuzzaman M. Effects of deep heat therapy on the patients with chronic low back pain. Mymensingh Med J. 2008;17(2):S32-8.

9. Ahmed MS, Shakoor MA, Khan AA. Evaluation of the effects of shortwave diathermy in patients with chronic low back pain. Bangladesh Med Res Counc Bull. 2009:35(1):18-20.

10. Moher D, Liberati A, Tetzlaff J, Altman DG. Preferred Reporting Items for Systematic Reviews and Meta-Analyses: The PRISMA Statement. Plos Medicine. 2009;6(7):e1000097.

11. Clarck HD, Wells GA, Huët C, McAlister FA, Salmi LR, Fergusson D, et al. Assessing the quality of randomized trials: reliability of the Jadad scale. Control Clin Trials. 1999;20(5):448-52.

12. Jadad AR, Moore RA, Carroll D, Jenkinson C, Reynolds DJM, Gavaghan DJ, et al. Assessing the quality of reports of randomized clinical trials: is blinding necessary? Control Clin Trials. $1996 ; 17(1): 1-12$

13. Downs SH, Black N. The feasibility of creating a checklist for the assessment of the metho- dological quality both of randomised and non-randomised studies of health care interventions. J Epidemiol Community Health. 1998;52(6):377-84

14. Gibson T, Grahame R, Harkness J, Woo P, Blagrave P, Hills R. Controlled comparison of short-wave diathermy treatment with osteopathic treatment in non-specific low back pain. Lancet. 1985;325(8440):1258-61.

15. Wagstaff P, Wagstaff S, Downie M. A pilot study to compare the efficacy of continuous and pulsed magnetic energy (short-wave diathermy) on the relief of low back pain. Physiother. 1986;72(11):563-6.

16. Sweetman BJ, Heinrich I, Anderson JAD. A randomized controlled trial of exercises, short wave diathermy, and traction for low back pain, with evidence of diagnosis-related response to treatment. J Orthop Rheumatol. 1993:4(6):159-66.

17. Shields N, Gormley J, O'Hare N. Short-Wave Diathermy: A Review of Existing Clinical Trials. Phys Ther Rev. 2001;6(2):101-18.

18. Belanger AY. Evidence-based Guide to Therapeutic Physical Agents. Philadelphia: Lippincott Williams \& Wilkins; 2002.

19. Kitchen S, Partridge C. Review of Shortwave Diathermy Continuous and Pulsed Patters Physiother. 1992;78(4):243-52.

20. Rawe IM. The case for over-the-counter shortwave therapy: safe and effective devices for pain management. Pain Manag. 2014;4(1):37-43

21. Al-Mandeel M, Watson T. An evaluative audit of patients' records in electrotherapy with specific reference to pulsed short wave therapy. Int J Ther Rehabil. 2006:13(9):414-9.

22. Al-Mandeel M, Watson T. The Thermal and Nonthermal Effects of High and Low Doses of Pulsed Short Wave Therapy (PSWT). Physiother Res Int. 2010;15(4):199-211.

23. Kerem M, Yigiter, K. Effects of continuous and pulsed short-wave diathermy in low back pain. Pain Clinic. 2002;14(1):55-9.

24. Durmus D, Ulus Y, Alayli G, Akyol Y, Bilgici A, Yazicioglu K, et al. Does microwave diathermy have an effect on clinical parameters in chronic low back pain? A randomized-controlled trial. J Back Musculoskelet Rehabil. 2014:27(4):435-43.

25. Teixeira MZ. Bases psiconeurofisiológicas do fenômeno placebo-nocebo: evidências científicas que valorizam a humanização da relação médico-paciente. Rev Assoc Med Bras. 2009;55(1):13-8.

26. Jayaram M, Kumar M, Raja R, Prashanta S, Rajeeva A, Veena J, et al. A comparative study of abdominal strengthening versus spinal extensors strengthening accompanied with SWD in reducing pain in chronic low back ache. J Evid Based Med. 2015;2(14):215-23.

27. Khan S, Shamsi S, Abdelkader S. Comparative Study of Short Wave Diathermy and Exercise Together and Exercise Alone in the Management of Chronic Back Pain. Int J Health Sci Res. 2013;3(9):7-14 